\title{
Proximal humerus fractures \\ Part 1: Conservative management
}

\author{
Anley $\mathrm{C}^{1}$ (1), Vrettos $\mathrm{BC}^{2}$, Rachuene $\mathrm{P}^{3}$, Roche SJL ${ }^{4}$
}

1 MBChB(Stell), FCS(SA)Orth, MMed (Ortho)(Stell); Consultant, Shoulder and Elbow Unit, Tygerberg Hospital, Division of Orthopaedics, Stellenbosch University

2 MBChB(Zim), FRCS(Eng), FCS(SA)Orth, MMed(Orth)(UCT); Associate Professor and Honorary Consultant, Shoulder and Elbow Unit, Groote Schuur Hospital, Division of Orthopaedics, University of Cape Town; Vincent Pallotti Hospital

3 MBChB(UL-Medunsa), FCS(SA)Orth, MMed Ortho (SMU); Fellow, Shoulder and Elbow Unit, Groote Schuur Hospital, Division of Orthopaedics, University of Cape Town

4 MBChB(UCT), FCS(SA)Orth; Associate Professor, Shoulder and Elbow Unit, Groote Schuur Hospital, Orthopaedic Research Unit and Orthopaedic Biomechanics Laboratory, Division of Orthopaedics, University of Cape Town

Corresponding author: Dr Cameron Anley, Medisuites 7, 9 Paul Kruger Street, Durbanville, 7550; tel: 021 9752890; email: drcameronanley@gmail.com

\begin{abstract}
Fractures of the proximal humerus are common, especially in osteoporotic females. Despite this, there remains significant debate around their preferred treatment. The difficulties when considering treatment options is the wide array of fracture patterns and multiple patient factors which play an important role in the outcome of the management of these fractures. Fortunately, the vast majority of these fractures can be treated conservatively. The challenge, however, is the $15 \%$ of patients in which surgery may be required such as displaced three- and four-part fractures, and fractures in young and active patients. Although various recent studies and review papers show acceptable results with conservative treatment, especially in elderly patients, the decision on when to operate and when to consider conservative treatment remains challenging. The goal of this current concepts paper is to highlight important aspects of the conservative management of patients with proximal humerus fractures, from initial assessment through to treatment, including possible complications.
\end{abstract}

Level of evidence: Level 5

Key words: fracture, proximal humerus, conservative, osteoporosis

Citation: Anley C, Vrettos BC, Rachuene P, Roche SJL. Proximal humerus fractures. Part 1: Conservative management SA Orthop J 2019;18(3):63-71. http://dx.doi.org/10.17159/2309-8309/2019/v18n3a8

Editor: Prof LC Marais, University of KwaZulu-Natal, Durban, South Africa

Received: July 2019

Accepted: July 2019

Published: August 2019

Copyright: $\odot 2019$ Anley C, et al. This is an open-access article distributed under the terms of the Creative Commons Attribution Licence, which permits unrestricted use, distribution and reproduction in any medium, provided the original author and source are credited.

Funding: No funding was received by any of the authors for this review.

Conflict of interest: The authors declare that there is no conflict of interest regarding the publication of this paper. 


\section{Introduction}

Proximal humerus fractures (PHFs) are common, accounting for $4-6 \%^{1-3}$ of all fractures, and more common in females over the age of 60 years due to the influence of osteoporosis. ${ }^{4,5}$

Many authors have suggested that up to $85 \%$ do not require surgery. ${ }^{4,6-8}$ Despite this, there appears to be a trend towards increased surgical intervention which has been attributed to newer designs of plating systems, as well as the promotion of the reverse shoulder replacement as a treatment option.6,7,9-12 The ideal outcome for a patient with a PHF is a pain-free shoulder with an acceptable range of motion according to the individual's specific functional requirements.

The decision about when to operate in order to achieve an acceptable outcome remains challenging, especially in older patients. $6,7,10,11$ Olerud has published results in which surgical outcome was superior; ${ }^{13}$ however, recent literature, ${ }^{9,14-17}$ including the well-publicised PROFHER trial, ${ }^{9}$ continues to promote the conservative management of PHFs. This discrepancy continues to create more questions than answers. Although there is criticism of these studies, they are changing the way that these fractures are approached.

The goal of this review is to try and clarify some of the current aspects related to the conservative management of PHFs. A second current concepts review article exploring the surgical options will be published in a later issue of this journal.

\section{Patient workup and classification}

\section{Clinical assessment}

A detailed history should be obtained to establish the mechanism of injury and to gain further information regarding comorbidities, social habits and previous functional status of the patient. Poor outcomes and increased risk of complications are associated with severe osteoporosis, smoking, drug and alcohol abuse, diabetes mellitus, rheumatoid arthritis, immunocompromise including steroid medication and concurrent neoplasm. ${ }^{4}$

A thorough assessment should be performed to exclude other injuries. Older patients are at risk of other common osteoporotic fractures of the neck of femur, distal radius and vertebra. Younger patients, whose injuries are more often the result of a significant trauma, are at risk of associated injures to the cervical spine, brachial plexus and the chest.

Vascular injuries may be masked by collateral circulation ${ }^{4,5}$ and further imaging should be considered if there is concern. Nerve injuries have been shown to be common (up to 67\%) with a previous study showing axillary nerve and the suprascapular nerve most commonly affected. In this study, these were diagnosed on electromyography (EMG) and the sensory fallout was noted to be low. Fortunately, most injuries did not have a clinical significance as they recovered but the authors did highlight that these patients had increased stiffness, possibly due to difficulties with the active aspect of their rehabilitation. ${ }^{18}$

\section{Radiological work-up}

Three X-ray views (Figure 1) should be routinely obtained to gain an understanding of the fracture configuration and prevent missing fragments which overlap with the humeral head or glenoid. A true shoulder AP (taken in line with the glenohumeral joint) can be used to assess the valgus or varus angulation of the head on the shaft, displacement of the shaft, a head split fracture, and to assess superior migration of a greater tuberosity fracture. On the lateral or scapular-Y view, a dislocation should be excluded, tuberosity

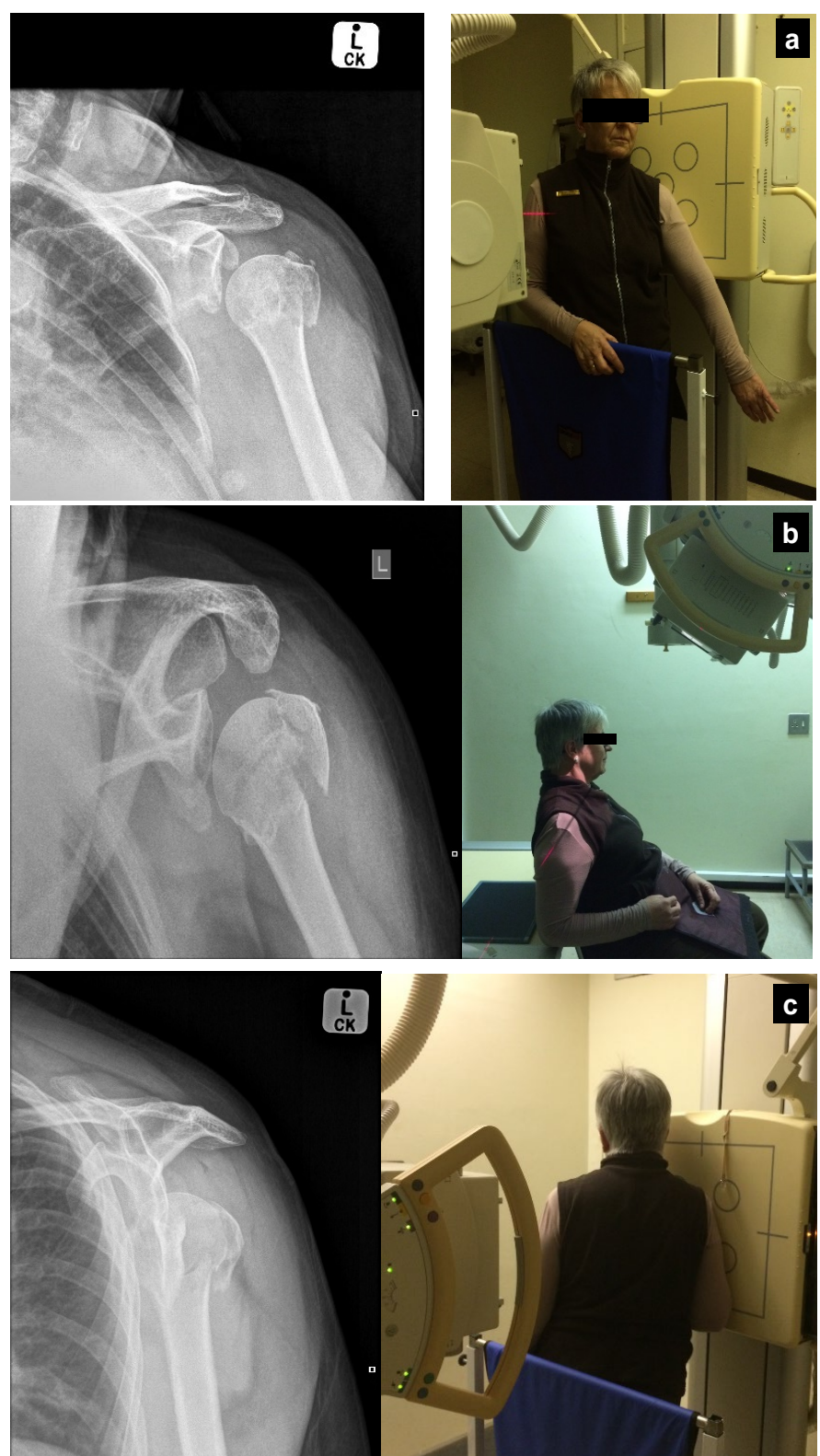

Figure 1. Suggested trauma series showing (a) AP view, (b) axillary view and (c) lateral view allowing excellent assessment of the fracture fragments and a demonstration of the how the X-rays are taken

fractures can be identified (especially posteriorly displaced fragments) and shaft displacement can be identified. Finally, an axillary view is essential. This is often poorly done due to the pain. In this situation, a modified axillary view or Valpeau view can be used to assess for a head split fracture, to exclude a dislocation and assess the displacement of the tuberosities which may be overlapping with the glenoid or humeral head on other views.

An impression of the bone quality can be obtained on a plain X-ray (Figure 2). The Tingart measurement was first described in 2003. ${ }^{19}$ On the AP view of the shoulder, the combined cortical thickness is calculated as the sum of the means of the medial and lateral cortical thickness at two levels and adjusted for the magnification factor. Level 1 is the most proximal level of the humeral diaphysis where the endosteal borders of the lateral and medial cortices are parallel to each other, with level 2 being $20 \mathrm{~mm}$ distal to level 1 . According to Tingart, a measurement of $<4 \mathrm{~mm}$ suggests poor bone quality. ${ }^{19}$

More recently Spross introduced the deltoid tuberosity index (DTI) on the AP view of the shoulder. ${ }^{20}$ The DTI is measured proximal 


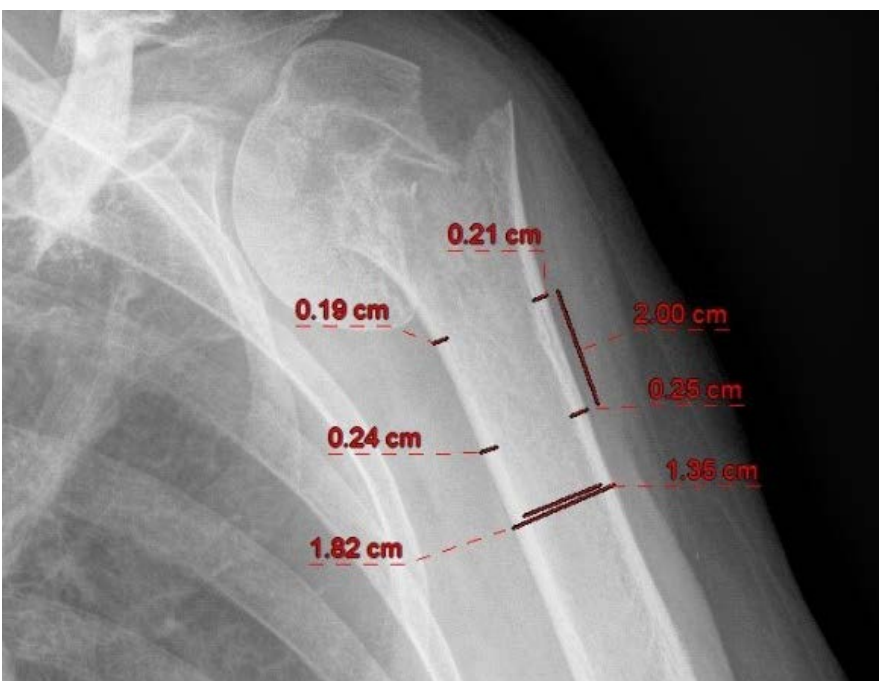

Figure 2. Showing the Tingart measurement $(2 \mathrm{~mm}+2.45 \mathrm{~mm}=4.5 \mathrm{~mm})$ and deltoid tuberosity index $(1.82 \mathrm{~cm} / 1.35 \mathrm{~cm}=1.35)$

to the deltoid tuberosity where the outer cortical border becomes parallel. At this level, the outer cortical diameter is divided by the inner endosteal diameter. A DTI $<1.4$ correlates to low bone mineral density of the humeral head. ${ }^{20}$ The advantages of the DTI are that, unlike the Tingart measurement, no adjustment for magnification is required and the area where the measurement is performed is not commonly affected by the fracture. This study suggested an improved sensitivity of the Tingart measurement if $5 \mathrm{~mm}$ was used as the cut-off. ${ }^{20}$

The indications for obtaining a computerised tomography (CT) scan for PHFs have not been well established. A recent study set out to establish indications but rather vaguely concluded that a CT should be obtained when sufficient information regarding the fracture pattern or extent cannot be obtained on good quality radiographs. ${ }^{21}$ Although there is no direct correlation with the fracture classification and the need for a $\mathrm{CT}$, more complex fractures will most commonly require a CT to assess fragment displacement (especially the tuberosities), assess the joint surface (especially with head split fractures), to assess the amount of comminution, and to exclude associated glenoid fractures. Although a CT can be used to assist with the decision when not to operate and possibly allow for better fracture classification, it plays a very important role in pre-operative planning when surgery is suggested. A CT allows the surgeon to appropriately assess the displaced fragments to ensure they are appropriately reduced during surgery. In addition, the benefit of 3D printing is being explored with promising results in assisting with pre-operative surgical planning. ${ }^{22}$

\section{Classification}

An ideal classification is one that is reproducible, best describes the pathology, and provides guidance on management of fractures. Codman first described PHF patterns by using anatomic drawings and it was from his work that the Neer and Hertel classifications were established. ${ }^{23,24}$

The Neer classification is the most widely used for evaluation of PHFs. His fracture descriptions coupled plain radiographs and intra-operative findings. He based his description on Codman's four-segment theory, dividing the proximal humerus into four important anatomical aspects, namely greater tuberosity, lesser tuberosity, humeral articular segment and the humeral shaft. Neer defined a part as displacement of either $1 \mathrm{~cm}$ or $45^{\circ}$ angulation. The fractures were then grouped into six groups depending on the displacement. Based on his classification system, Neer described associated soft tissue injuries and guided the management of PHFs. Various studies have demonstrated poor inter- and intra-observer reliability of the Neer classification. ${ }^{24-26}$ Other limitations of this system have been attributed to difficulty in defining and estimating the extent of displacement. ${ }^{24}$ Results of the Neer classification on 3D CT images are mixed. ${ }^{24,25,27}$ In an attempt to improve on the Neer classification, multiple other classification systems have been published.

The AO group described a more detailed classification system in 1990 with more fracture configurations than Neer's. Hertel has been the biggest critique of the Neer classification and recently he described a classification system based on Codman's original drawings to describe fracture planes and impact on humeral head perfusion. ${ }^{28}$ Resch et al. described a classification based on the pathomorphological analysis of PHFs on 3D CT scans. Once again studies showed poor interobserver reliability in more complex fractures. ${ }^{29}$ These systems have failed to improve on limitations of the Neer classification in clinical practice and their use seems to be purely academic. ${ }^{25,26}$

The ability of artificial intelligence (AI) to accurately diagnose and classify PHFs has been explored with excellent results (96\% accuracy) in diagnosing a fracture and promising results (65-86\% accuracy) with regard to classification of the fractures when using the Neer classification. ${ }^{30}$ These results were similar to those obtained by specialist shoulder surgeons. The authors suggest that the Al results will continue to improve with time. Unfortunately, Al does not yet address the management of PHFs.

\section{Management}

As with most fractures in orthopaedics, the decision whether to operate or not is multifactorial considering both patient factors and fracture configuration. A lack of large sample comparative studies makes decision-making difficult. Current trends show increases in surgical management of $\mathrm{PHFs}^{6,11,12}$ and confirms a lack of consensus on choice of treatment among surgeons. ${ }^{7,31}$ This is illustrated in a recent study in which three experienced shoulder surgeons only unanimously agreed on treatment in $51 \%$ of 274 cases. In the cases in which unanimous agreement was achieved, the patients underwent the selected treatment $63.5 \%$ of the time. Finally, they concluded the successful management of displaced PHFs requires not only the technical ability to adequately perform surgical treatment but also, perhaps more importantly, the critical ability to decide when patients should undergo conservative or operative treatment.

A variety of newer studies and review articles have advocated the use of conservative management of PHFs, 9,14-17,32 showing no significant difference in outcome between surgery and conservative management even in three- and four-part fractures. ${ }^{33,34}$ It is important to note, however, that the average age in most of these studies is older than 65 years, and thus there remains a risk that these conclusions are applied across the board, including to a younger population of patients, who will naturally have higher physical demands and expectations. This was highlighted in the 2015 Cochrane review ${ }^{17}$ as well as a recent meta-analysis on PHFs. ${ }^{16}$

The PROFHER trial has recently published the five-year results of the initial trial, in which 250 patients were randomly assigned into conservative or surgical treatment. Patients were eligible for inclusion if they were aged 16 years or older and presented within three weeks of sustaining a displaced fracture of the proximal humerus that involved the surgical neck. ${ }^{9}$ The majority of patients had two- or three-part fractures. The degree of displacement had to be sufficient for the treating surgeon to consider surgical intervention. The original trial concluded that there was no significant 


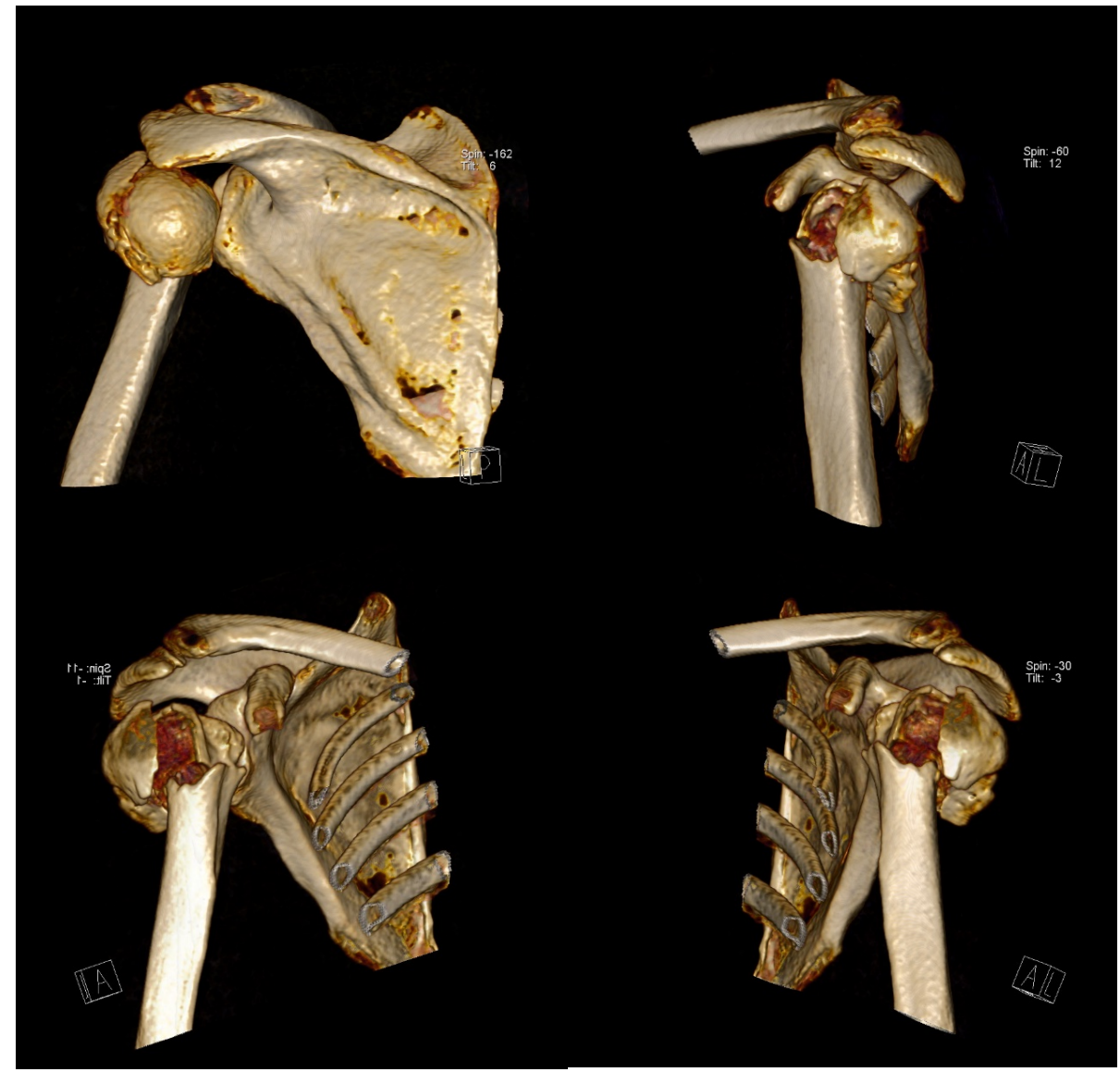

Figure 3a. CT scan of a patient with a proximal humerus fracture

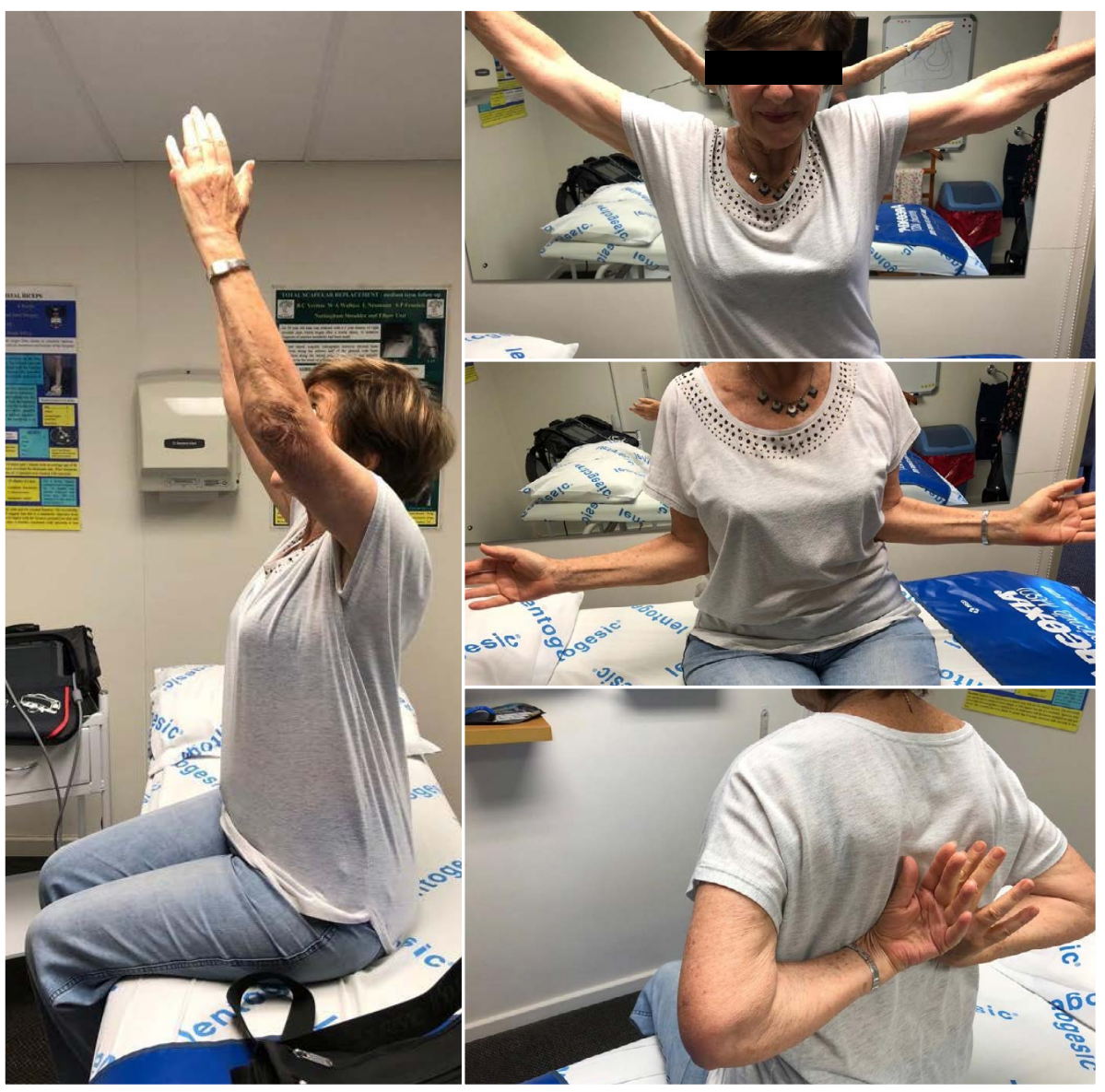

Figure 3c. Clinical pictures to show range of motion and a successful outcome following conservative management (with above CT scan)

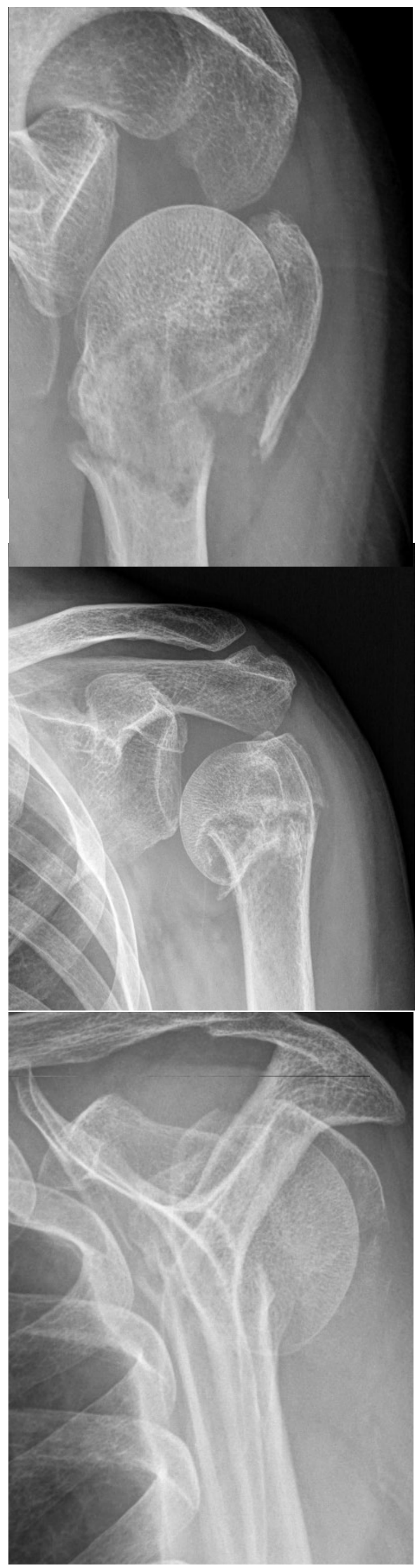

Figure $3 b$. X-rays at union 
difference in patient-reported clinical outcomes between surgical treatment compared with non-surgical treatment over two years following fracture occurrence in patients with displaced proximal humeral fractures involving the surgical neck. These results were sustained at the five-year follow-up. ${ }^{32}$

The average age in the two groups was similar (surgical: 66.60 years vs non-surgical: 65.43 years) with a standard deviation (SD) of 11.80 and 12.03 respectively, implying that most patients included were older than 55 years. A variety of other limitations of the PROFHER trial have been highlighted including high exclusion rate, the bias introduced by surgeons by excluding patients who they deemed definitely required surgery, small numbers treated by each centre with various levels of expertise, and surgical treatment being not specific with either open reduction and internal fixation (ORIF) or arthroplasty being done.

One of the difficulties with any research in PHFs is the array of different fracture patterns leading to small numbers of certain fracture types in trials such as the PROFHER trial. A more recent meta-analysis ${ }^{16}$ pooled the data of 22 studies (both randomised control studies and observational studies) resulting in a metaanalysis of 1743 patients with displaced PHFs (including the patients from the PROFHER trial): 910 treated operatively and 833 non-operatively. The results showed there was no difference in physical function as measured with the Constant-Murley score when comparing operative and non-operative treatment. The authors acknowledge the limitations of a meta-analysis but this well-conducted review again recommends the non-operative treatment for the average elderly patient (aged $>65$ years) with a displaced PHF. ${ }^{16}$

From these two papers and a 2015 Cochrane review it now seems clear that there is justification to consider conservative treatment in patients over the age of 65 years. This is demonstrated in Figure 3. Two important questions remain: the preferred treatment of displaced three- and four-part fractures in elderly patients and the management of PHFs in young patients.

The use of the reverse shoulder replacement has been advocated for management of displaced Neer three- and four-part fractures in elderly patients. ${ }^{35,36}$ Once again, however, this is debated in the literature. The previously cited meta-analysis included a reasonable number of four-part fractures (21\%). A subgroup analysis of Neer three- and four-part fractures showed no difference in outcome. This is supported in a paper comparing the outcome of reverse total shoulder versus conservative treatment (patients who refused surgery) for three- and four-part fractures, concluding that there was no difference in outcome at one year. This is now the topic of the PROFHER 2 trial which has recently started recruiting. This involves patients over the age of 65 years with Neer threeand four-part fractures being randomised into conservative, hemiarthroplasty or reverse shoulder replacement.

A second concern which is highlighted is the management of PHFs in younger, active patients. The lack of research related to the management of this group of patients has been highlighted in the literature. ${ }^{16,17}$ The amount of acceptable displacement or angulation is often based on small sample studies, author opinion or biomechanical studies and has not been specifically demonstrated in clinical trials. The dilemma we currently have is trying to predict who may be left with a symptomatic malunion.

The absolute indications for surgery (in any age group) are fairly universally accepted and include three- and four-part fractures in conjunction with a dislocation, head splitting fractures, pathological (other than osteoporosis) fractures, open fractures, and fractures associated with a vascular injury.,
Relative indications are not as clearly defined and are more commonly applied to younger and more active patients. Current relative indications include displaced tuberosity fractures, an unstable configuration of the surgical neck (disengagement of the head due to displacement, $>50 \%$ displacement or comminution) and varus or valgus angulation of $>30^{\circ}$ from the normal $130^{\circ} .4,5$ Valgus deformity has been shown to have a worse outcome. ${ }^{37}$

The acceptable displacement of the tuberosities varies among authors ranging from $3 \mathrm{~mm}$ to $1 \mathrm{~cm}^{4,38-40}$ and differs between superior and posterior displacement. The majority of authors appear to have reduced the original guidelines of $1 \mathrm{~cm}$ described by Neer to $5 \mathrm{~mm}$ displacement in all directions. This is supported by small clinical trials showing better outcomes ${ }^{38}$ and biomechanical evidence demonstrating a significant difference in the force required to abduct the arm with a $5 \mathrm{~mm}$ change in position of the tuberosity. ${ }^{41} \mathrm{~A}$ recent review article suggested surgical intervention for more than $5 \mathrm{~mm}$ of superior displacement and concluded that there are no clear guidelines for posterior displacement but notes poor outcomes if left untreated. ${ }^{40}$

Spross et al. have recently published a new algorithm (Figure 4) which differentiates between patients based on age (65 years) and activity level after which the fracture pattern and displacement is considered. These authors have published the results of 160 patients treated according to their proposed treatment algorithm with very satisfying overall results with low complication and revision rates. ${ }^{42}$ Although further verification is required, this algorithm highlights important aspects to consider when treating a patient with a PHF.

Currently most outcome scores focus on pain, sleep and function. A recent study looking into the importance of these factors in older patients with PHFs concluded that improved function is less important than reduced pain and better sleep. ${ }^{43}$ This paper highlights that maybe we are measuring the wrong outcomes when assessing the outcomes of fractures. This will require further investigation going forward.

\section{Conservative management}

Once conservative management has been decided upon, important factors to consider are the type of sling and the length of immobilisation time. A simple sling has shown to be adequate along with appropriate analgesia for comfort. There is no benefit to a hanging cast as they have been shown not to improve the alignment and they may in fact increase the risk of a non-union by causing distraction at the fracture site. ${ }^{4,44-46}$ If there is uncertainty about the need for surgery, a common practice is to give a trial of conservative treatment for a week or two to allow for reassessment. An X-ray should be considered at one to two weeks to ensure there has not been further displacement of the fracture.

Various studies have confirmed that prolonged immobilisation is not required and thus a short period of two to three weeks immobilisation followed by physiotherapy is suggested as improved recovery has been shown when physiotherapy commences early. ${ }^{4,5,46-49} \mathrm{~A}$ recent meta-analysis showed a better patient quality of life score for the first three to six months with early mobilisation. ${ }^{50}$ No specific physiotherapy programme has proven to be superior.

When treating PHFs, all patient factors should be assessed and factored into the management particularly paying attention to the fact that PHFs are the fourth most common osteoporotic fractures. Any patient presenting with a PHF should therefore be seen as an opportunity to make the diagnosis of osteoporosis and initiate the appropriate management. The literature shows poor initiation of treatment for osteoporosis following a $\mathrm{PHF}^{51}$ which is worrying given that a recent study of over 1 million fragility fractures $(13.1 \%$ 
Young and active patients with good bone quality (healthy worker $<65$ years)
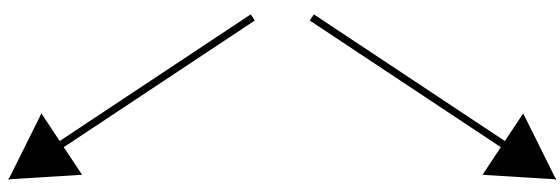

One-part fracture

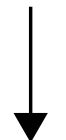

$>5 \mathrm{~mm}$ displacement of the greater or

lesser tuberiosity

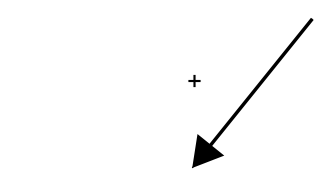

ORIF or Arthroscopic RIF

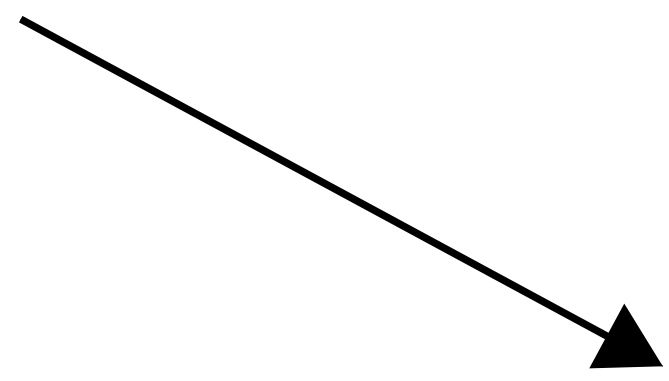

2-, 3-, 4-part and

fracture dislocations

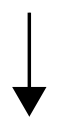

Valgus impacted

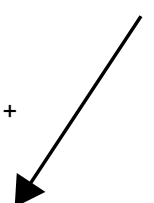

One-third tubular plate ORIF

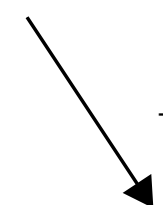

Stable and anatomical reconstruction possible

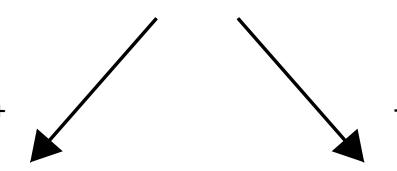

Locking plate ORIF

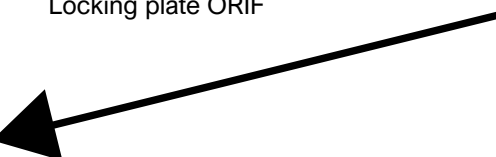

Hemiarthroplasty

Elderly patient $>65$ years

Active and autonomous

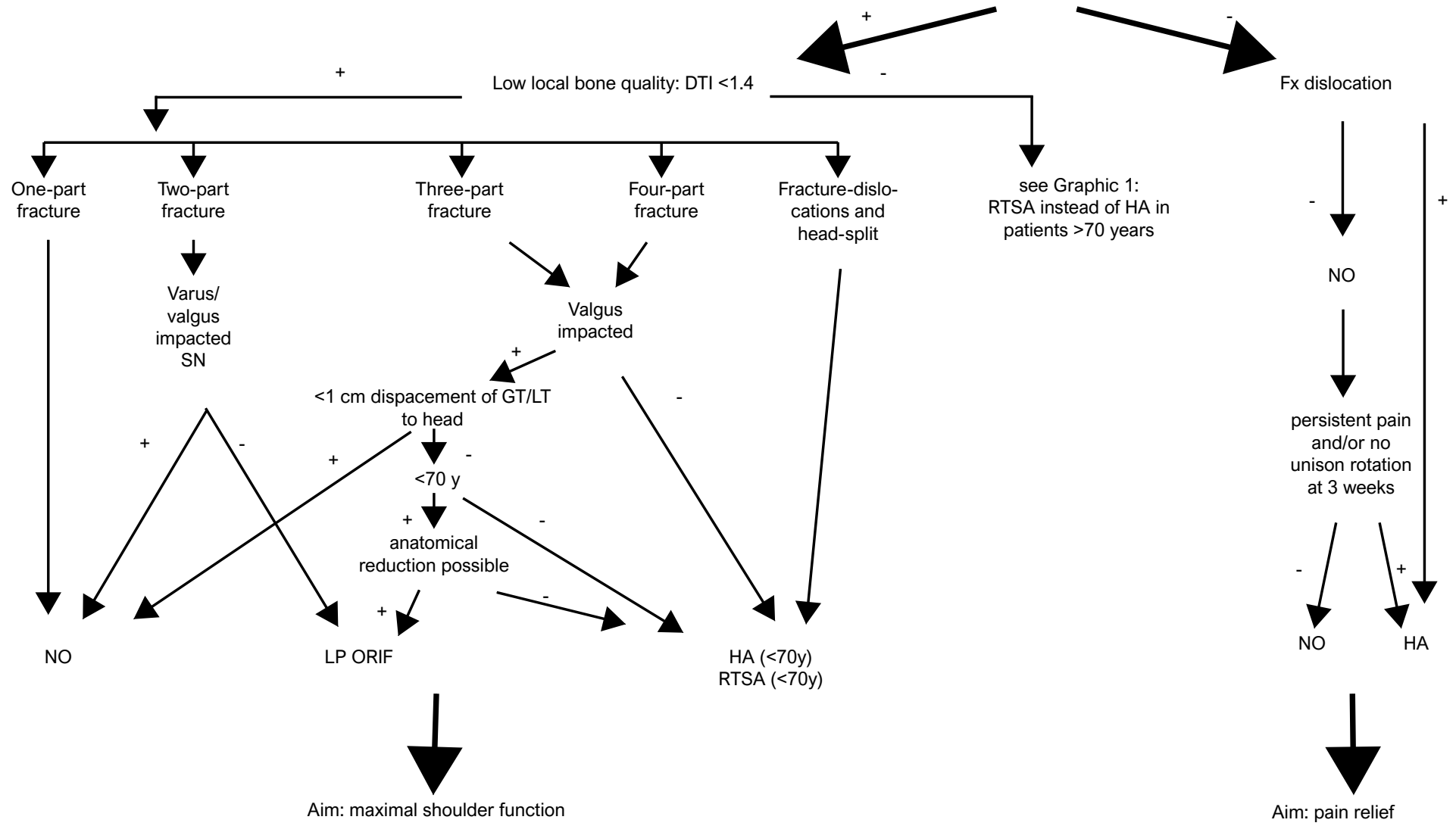

Figure 4. The algorithm as presented by Spross et al. ${ }^{42}$ (adapted from the original and used with permission) 
of which were PHFs) reported a $13.2 \%$ chance of a second fragility fracture within three years of a PHF. This second fragility fracture was most likely to be a neck of femur fracture with a $21.3 \%$ mortality rate at one year'. ${ }^{2}$ It has been shown that a well-run screening and treatment programme can reduce the risk of a primary PHF fragility fracture by $45 \%$, and that anti-osteoporosis treatment started after a fragility fracture can decrease the age- and sex-adjusted risk of a subsequent fracture by $52 \%$ in patients with a PHF as the index fracture. ${ }^{53,54}$

\section{Complications of conservative treatment}

The most common and important complications associated with conservative treatment of PHFs are avascular necrosis (AVN), symptomatic malunion and non-union (1.1-10\%). ${ }^{45,55}$

\section{AVN}

The physiology around the development of AVN remains poorly understood. ${ }^{4}$ Hertel initially tried to quantify the risk of AVN suggesting that fractures with a metaphyseal head extension of $<8 \mathrm{~mm}$ and medial hinge disruption $>2 \mathrm{~mm}$ correlated strongly with humeral head ischaemia. ${ }^{28} \mathrm{He}$ later acknowledged in a followup article that this ischaemia did not necessarily predict AVN ${ }^{56}$ In addition, there is little evidence to show that surgical realignment reduces the risk of $\mathrm{AVN}$; $^{16}$ in fact, poor technique and excessive surgical periosteal stripping may increase the risk. ${ }^{4}$ The most common treatment of symptomatic AVN is arthroplasty.

\section{Non-union}

The risk of non-union following a PHF is low, reported as $1.1 \%$, increasing to $8 \%$ with metaphyseal comminution and $10 \%$ with significant displacement of the surgical neck. ${ }^{57}$ Although surgery might slightly reduce the chance of non-union, comparative studies have not shown a significant reduction related to surgery. Factors which are likely to predispose to non-union include: patient factors like malnutrition, poorly controlled medical comorbidities, smoking and alcohol abuse; fracture factors including severe comminution and severe displacement of the humeral head; and treatment factors such as distraction due to a hanging cast or extensive shoulder mobilisation. ${ }^{4,57-60}$ The treatment of patients presenting with pain and loss of function should be individualised, but both ORIF with bone grafting and a reverse shoulder arthroplasty have been advocated. $4,61,62$ The absence of arthritis or AVN, adequate humeral bone stock, and absence of malunion of the tuberosities are required before considering ORIF.4 $A$ few small studies have reported the use of the reverse shoulder arthroplasty as a salvage procedure for PHF non-unions. Although good results have been reported, a high complication rate, especially dislocation, was noted. 62

\section{Malunion}

The degree of acceptable malunion has not been fully defined hence the uncertainty around the acceptable parameters for conservative treatment. An important factor is the age and expectations of the patient; as expected, older patients will tolerate a malunion better than younger patient. ${ }^{4}$ Concerns related to malunion are cuff dysfunction and impingement which can be difficult to address post union. A CT should be obtained (ideally including elbow cuts to fully assess rotational malunion) if surgical intervention is required. Treatment options such as osteotomies and arthroplasty (including the new stemless prosthesis) have been described depending on the type and extent of the malunion. ${ }^{63}$

\section{Mortality}

Osteoporotic fractures are associated with mortality rates above those of the general population ranging from $1 \%$ during the initial admission to $10 \%$ at a year following the fracture. ${ }^{64,65}$ Patients who live at nursing homes are at higher risk of mortality than those who live in their own homes. ${ }^{65}$ Although no specific protocols exist, the early involvement of a physician is recommended on admission to assist with the medical care of patients with PHFs.

\section{Delayed vs early reverse total shoulder replacement}

An important question related to the treatment of PHFs is whether the results of a salvage arthroplasty procedure, particularly a reverse shoulder replacement, are equivalent to a primary reverse arthroplasty at time of fracture. We have to rely on reviews and metaanalysis, as the published studies are small case series. A recent meta-analysis suggests that there is no difference in outcome; in fact, there was improved external rotation in the delayed group. ${ }^{66}$ This would imply that it is not detrimental to try a conservative approach initially, knowing that it remains possible to obtain as good a result if a reverse total shoulder replacement needs to performed as a salvage procedure. ${ }^{66}$ This approach potentially subjects patients to a longer period of pain and immobility with delayed surgery, and this should be discussed with the patient. This was slightly contradictory to a previous paper which showed improved tuberosity healing and external rotation when a reverse is performed for an acute fracture. ${ }^{67}$ The newer stemless implants have been advocated as a possible solution for the challenges of an arthroplasty in the face of a malunion; however, long-term follow-up is still required for this indication.

\section{Conclusion and summary}

In conclusion, despite being a common fracture the treatment remains widely debated. The majority of PHFs can be managed conservatively. The current literature supports the conservative management in older patients, even in three- and four-part fractures. In these patients, a reverse shoulder replacement appears be available as a salvage procedure.

A more aggressive approach is generally advocated for younger patients. Relative indications are displaced tuberosity fractures, an unstable configuration of the surgical neck, and varus or valgus angulation.

Conservative management, when advocated, consists of a simple master sling and early mobilisation with physiotherapy. Complications are rare; once again the reverse shoulder replacement appears to be available as a salvage procedure.

\section{Learning points}

The majority of proximal humerus fractures can be treated conservatively with an acceptable outcome.

Proximal humerus fractures are common osteoporotic fractures and should be an opportunity to confirm the diagnosis and start treatment of osteoporosis.

The treatment of three- and four-part proximal humerus fractures in elderly patients remains challenging but conservative treatment may be acceptable.

A more aggressive approach remains advocated for younger patients.

Conservative management, when advocated, consists of a simple master sling and early mobilisation with physiotherapy. 


\section{Declarations}

The authors declare authorship of this article and that they have followed sound scientific research practice. This research is original and does not transgress plagiarism policies.

\section{Author contributions}

CA was the primary author. BV reviewed the written submission. PR assisted with the writing and reviewed the written submission. SR assisted with the writing and reviewed the written submission.

\section{ORCID}

C Anley (ID https://orcid.org/0000-0002-5983-3520

\section{References}

1. Court-Brown CM, Caesar B. Epidemiology of adult fractures: a review. Injury. 2006;37(8):691-97.

2. Palvanen $\mathrm{M}$ et al. Update in the epidemiology of proximal humeral fractures. Clin Orthop Related Research 2006;442:87-92.

3. Lind T, Krøner K, Jensen J. The epidemiology of fractures of the proximal humerus. Arch Orthop Trauma Surg 1989;108:285-87.

4. Murray IR, Amin AK, White TO, Robinson CM. Proximal humeral fractures: current concepts in classification, treatment and outcomes. The Journal of Bone and Joint Surgery. British volume. 2011 Jan;93(1):1-11.

5. Maier D, Jaeger M, Izadpanah K, Strohm PC, Suedkamp NP. Proximal humeral fracture treatment in adults. JBJS. 2014 Feb 5;96(3):251-61.

6. Bell JE, Leung $\mathrm{BC}$, Spratt KF, et al. Trends and variation in incidence, surgical treatment, and repeat surgery of proximal humeral fractures in the elderly. J Bone Joint Surg Am. 2011;93(2):121-31.

7. LaMartina II J, Christmas KN, Simon P, Streit JJ, Allert JW, Clark J, Otto RJ, Abdelfattah A, Mighell MA, Frankle MA. Difficulty in decision making in the treatment of displaced proximal humerus fractures: the effect of uncertainty on surgical outcomes. Journal of Shoulder and Elbow Surgery. 2018 Mar 1;27(3):470-77.

8. Roche SJ, Vrettos BC. Surgery for displaced three-and four-part proximal humeral fractures: The rationale for our approach. $S A$ Orthopaedic Journal. 2008 Sep;7(3):16-21.

9. Rangan A, Handoll H, Brealey S, Jefferson L, Keding A, Martin BC, Goodchild L, Chuang LH, Hewitt C, Torgerson D. Surgical vs nonsurgical treatment of adults with displaced fractures of the proximal humerus: the PROFHER randomized clinical trial. JAMA. 2015 Mar 10;313(10):1037-47.

10. Spross C, Meester J, Mazzucchelli RA, Puskás GJ, Zdravkovic V, Jost B. Evidence-based algorithm to treat patients with proximal humerus fractures-a prospective study with early clinical and overall performance results. Journal of Shoulder and Elbow Surgery. 2019 Jun 1;28(6):1022-32.

11. Khatib O, Onyekwelu I, Zuckerman JD. The incidence of proximal humeral fractures in New York State from 1990 through 2010 with an emphasis on operative management in patients aged 65 years or older. Journal of Shoulder and Elbow Surgery. 2014 Sep 1;23(9):1356-62.

12. Huttunen TT, Launonen AP, Pihlajamäki H, Kannus $P$, Mattila VM. Trends in the surgical treatment of proximal humeral fractures-a nationwide 23-year study in Finland. BMC Musculoskeletal Disorders. 2012 Dec;13(1):261.

13. Olerud P, Ahrengart L, Ponzer S, Saving J, Tidermark J. Internal fixation versus nonoperative treatment of displaced 3-part proximal humeral fractures in elderly patients: a randomized controlled trial. Journal of Shoulder and Elbow Surgery. 2011 Jul 1;20(5):747-55.

14. Rabi S, Evaniew N, Sprague SA, Bhandari M, Slobogean GP. Operative vs non-operative management of displaced proximal humeral fractures in the elderly: a systematic review and meta-analysis of randomized controlled trials. World $\mathrm{J}$ Orthop 2015;6:838-46.

15. Xie L, Ding F, Zhao Z, Chen Y, Xing D. Operative versus non-operative treatment in complex proximal humeral fractures: a meta-analysis of randomized controlled trials. Springerplus. 2015 Dec;4(1):728
16. Beks RB, Ochen $Y$, Frima $H$, Smeeing DP, van der Meijden $O$, Timmers TK, van der Velde D, van Heijl M, Leenen LP, Groenwold $\mathrm{RH}$, Houwert RM. Operative versus nonoperative treatment of proximal humeral fractures: a systematic review, meta-analysis, and comparison of observational studies and randomized controlled trials. Journal of Shoulder and Elbow Surgery. 2018 Aug 1;27(8):1526-34.

17. Handoll $\mathrm{HH}$, Brorson S. Interventions for treating proximal humeral fractures in adults. Cochrane Database Syst Rev 2015;(11):CD000434.

18. Visser CP, Coene LN, Brand R, Tavy DL. Nerve lesions in proximal humeral fractures. Journal of Shoulder and Elbow Surgery. 2001 Sep 1;10(5):421-27.

19. Tingart MJ, Apreleva M, von Stechow D, Zurakowski D, Warner JJ. The cortical thickness of the proximal humeral diaphysis predicts bone mineral density of the proximal humerus. The Journal of Bone and Joint Surgery. British volume. 2003 May;85(4):611-17.

20. Spross C, Kaestle N, Benninger E, Fornaro J, Erhardt JB, Zdravkovic V, et al. Deltoid tuberosity index: a simple radiographic tool to assess local bone quality in proximal humerus fractures. Clin Orthop Relat Res 2015;473:3038-45.

21. Bahrs C, Rolauffs B, Südkamp NP, Schmal H, Eingartner C, Dietz K, Pereira PL, Weise K, Lingenfelter E, Helwig P. Indications for computed tomography (CT-) diagnostics in proximal humeral fractures: a comparative study of plain radiography and computed tomography. BMC musculoskeletal Disorders. 2009 Dec;10(1):33.

22. You W, Liu LJ, Chen HX, Xiong JY, Wang DM, Huang JH, Ding JL, Wang DP. Application of 3D printing technology on the treatment of complex proximal humeral fractures (Neer 3-part and 4-part) in old people. Orthopaedics \& Traumatology: Surgery \& Research. 2016 Nov 1;102(7):897-903.

23. Neer CS2. Displaced proximal humerus fractures: Part I. Classifications and evaluation. J Bone Joint Surg Am. 1970; 52(223): p. 1077-89

24. Carofino BC, Leopold SS. Classifications in brief: the Neer classification for proximal humerus fractures. Clin Orthop Relat Res. 2013;471:39-43.

25. Bernstein JA, Adler LM, Dalsey RM, Williams GR, lannotti JP Evaluation of the Neer system of classification of proximal humerus fractures with computerized tomographic scans and plain x-rays. $J$ Bone Joint Surg Am. 1996;78:1371-75.

26. Majed A, Macleod I, Bull AM, Zyto K, Resch H, Hertel R, et al. Proximal humeral fracture classification systems revisited. $J$ Shoulder Elbow Surg. 2011 Oct;20(7):1125-32.

27. Brunner A, Honigmann P, Treutmann T, Babst R. The impact of stereo-visualisation of three-dimensional CT datasets on the interand intraobserver reliability of the AO/OTA and Neer classifications in the assessment of fractures of the proximal humerus. $J$ Bone Joint Surg Br. 2009;91:766-71.

28. Hertel R, Hempfing A, Stiehler M, Leunig M. Predictors of humeral head ischaemia after intracapsular fracture of the proximal humerus. J Shoulder Elbow Surg. 2004 Jul/Aug;13(4):427-33.

29. Resch H, Tauber M, Neviaser RJ, Neviaser AA, Majed A, Hasley $\mathrm{T}$, et al. Classification of proximal humeral fractures based on a pathomorphologic analysis. J Shoulder Elbow Surg. 2016 March;25(3):455-62.

30. Chung SW, Han SS, Lee JW, Oh KS, Kim NR, Yoon JP, Kim JY, Moon SH, Kwon J, Lee HJ, Noh YM. Automated detection and classification of the proximal humerus fracture by using deep learning algorithm. Acta orthopaedica. 2018 Jul 4;89(4):468-73.

31. Floyd SB, Campbell J, Chapman CG, Thigpen CA, Kissenberth MJ, Brooks JM. Geographic variation in the treatment of proximal humerus fracture: an update on surgery rates and treatment consensus. Journal of Orthopaedic Surgery and Research. 2019 Jan;14(1):22.

32. Handoll $\mathrm{HH}$, Keding A, Corbacho B, Brealey SD, Hewitt C, Rangan A. Five-year follow-up results of the PROFHER trial comparing operative and non-operative treatment of adults with a displaced fracture of the proximal humerus. The Bone \& Joint Journal. 2017 Mar;99(3):383-92.

33. Roberson TA, Granade CM, Hunt Q, Griscom JT, Adams KJ, Momaya AM, Kwapisz A, Kissenberth MJ, Tolan SJ, Hawkins RJ, Tokish JM. Nonoperative management versus reverse shoulder arthroplasty for treatment of 3-and 4-part proximal humeral fractures in older adults. Journal of Shoulder and Elbow Surgery. 2017 Jun 1:26(6):1017-22. 
34. Li $Y$, Zhao $L$, Zhu $L$, Li J, Chen A Internal fixation versus nonoperative treatment for displaced 3-part or 4-part proxima humeral fractures in elderly patients: a meta-analysis of randomized controlled trials. PloS one. 2013 Sep 16;8(9):e75464.

35. Jobin CM, Galdi B, Anakwenze OA, Ahmad CS, Levine WN Reverse shoulder arthroplasty for the management of proximal humerus fractures. JAAOS-Journal of the American Academy of Orthopaedic Surgeons. 2015 Mar 1;23(3):190-201.

36. Mata-Fink A, Meinke M, Jones C, Kim B, Bell JE. Reverse shoulder arthroplasty for treatment of proximal humeral fractures in older adults: a systematic review. Journal of Shoulder and Elbow Surgery. 2013 Dec 1;22(12):1737-48.

37. Foruria AM, de Gracia MM, Larson DR, Munuera L, SanchezSotelo J. The pattern of the fracture and displacement of the fragments predict the outcome in proximal humeral fractures. $J$ Bone Joint Surg Br. 2011 Mar;93(3):378-86.

38. Platzer P, Kutscha-Lissberg F, Lehr S, Vecsei V, Gaebler C: The influence of displacement on shoulder function in patients with minimally displaced fractures of the greater tuberosity. Injury 2005;36(10):1185-89.

39. Rath E, Alkrinawi N, Levy O, Debbi R, Amar E, Atoun E: Minimally displaced fractures of the greater tuberosity: Outcome of non-operative treatment. J Shoulder Elbow Surg 2013;22(10):e8-e11.

40. Rouleau DM, Mutch J, Laflamme GY. Surgical treatment of displaced greater tuberosity fractures of the humerus. JAAOS-Journal of the American Academy of Orthopaedic Surgeons. 2016 Jan 1;24(1):46-56

41. Bono CM, Renard R, Levine RG, Levy AS: Effect of displacement of fractures of the greater tuberosity on the mechanics of the shoulder. J Bone Joint Surg Br 2001;83(7):1056-62.

42. Spross C, Meester J, Mazzucchelli RA, Puskás GJ, Zdravkovic V, Jost B. Evidence-based algorithm to treat patients with proximal humerus fractures-a prospective study with early clinical and overall performance results. Journal of Shoulder and Elbow Surgery. 2019 Jun 1;28(6):1022-32.

43. Sabharwal S, Archer S, Cadoux-Hudson D, Griffiths D, Gupte $\mathrm{CM}$, Reilly P. Exploring elderly patients' experiences of recovery following complex proximal humerus fracture: A qualitative study. Journal of Health Psychology. 2019 May 30:1-12.

44. Leyshon RL. Closed treatment of fractures of the proximal humerus. Acta Orthop Scand 1984;55:48-51.

45. Rasmussen S, Hvass I, Dalsgaard J, Christensen BS, Holstad E. Displaced proximal humeral fractures: results of conservative treatment. Injury 1992;23:41-43.

46. Vachtsevanos L, Hayden L, Desai AS, Dramis A. Management of proximal humerus fractures in adults. World journal of Orthopedics. 2014 Nov 18;5(5):685-93.

47. Kancherla VK, Singh A, Anakwenze OA. Management of acute proximal humeral fractures. JAAOS-Journal of the American Academy of Orthopaedic Surgeons. 2017 Jan 1;25(1):42-52.

48. Kristiansen B, Angermann P, Larsen TK. Functional results following fractures of the proximal humerus. A controlled clinical study comparing two periods of immobilization. Arch Orthop Trauma Surg 1989;108:339-41.

49. Lefevre-Colau MM, Babinet A, Fayad F, Fermanian J, Anract P, Roren A, Kansao J, Revel M, Poiraudeau S. Immediate mobilization compared with conventional immobilization for the impacted nonoperatively treated proximal humeral fracture. A randomized controlled trial. J Bone Joint Surg Am 2007;89:2582-90.

50. Punnoose A, Fisk R, Triggs F, Gibbins N, Harvey-Hyde M. Rehabilitation of conservatively managed proximal humerus fractures: a systematic review of the literature. Physiotherapy. 2019 Jan 1;105:e15.

51. Viprey M, Caillet P, Canat G, Jaglal S, Haesebaert J, Chapurlat R, Schott AM. Low osteoporosis treatment initiation rate in women after distal forearm or proximal humerus fracture: a healthcare database nested cohort study. PloS one. 2015 Dec 2;10(12).

52. Dang DY, Zetumer S, Zhang AL. Recurrent fragility fractures: a cross-sectional analysis. JAAOS-Journal of the American Academy of Orthopaedic Surgeons. 2019 Jan 15;27(2):e85-91.

53. Singh A, Adams AL, Burchette R, Dell RM, Funahashi TT, Navarro RA. The effect of osteoporosis management on proximal humeral fracture. Journal of Shoulder and Elbow Surgery. 2015 Feb 1;24(2):191-98.
54. Bawa HS, Weick J, Dirschl DR. Anti-osteoporotic therapy after fragility fracture lowers rate of subsequent fracture: analysis of a large population sample. JBJS. 2015 Oct 7;97(19):1555-62.

55. Cadet ER, Yin B, Schulz B, Ahmad CS, Rosenwasser MP. Proximal humerus and humeral shaft nonunions. J Am Acad Orthop Surg 2013;21:538-47.

56. Bastian JD, Hertel R: Initial post-fracture humeral head ischemia does not predict development of necrosis. J Shoulder Elbow Surg 2008;17(1):2-8.

57. Court-Brown CM, McQueen MM. Nonunions of the proximal humerus: their prevalence and functional outcome. J Trauma. 2008;64:1517-21.

58. Healy WL, Jupiter JB, Kristiansen TK, White RR. Nonunion of the proximal humerus: a review of 25 cases. $J$ Orthop Trauma 1990;4:424-31.

59. Scheck M. Surgical treatment of nonunions of the surgical neck of the humerus. Clin Orthop 1982;167:255-59.

60. Volgas DA, Stannard JP, Alonso JE. Nonunions of the humerus. Clin Orthop 2004;419:46-50.

61. Quadlbauer S, Hofmann GJ, Leixnering M, Rosenauer R, Hausner $\mathrm{T}$, Reichetseder J. Open reduction and fixation with a locking plate without bone grafting is a reasonable and safe option for treating proximal humerus nonunion. International Orthopaedics. $2018 \mathrm{Sep}$ 1;42(9):2199-209.

62. Zafra M, Uceda P, Flores M, Carpintero P. Reverse total shoulder replacement for nonunion of a fracture of the proximal humerus. The Bone \& Joint Journal. 2014 Sep;96(9):1239-43.

63. Duparc F. Malunion of the proximal humerus. Orthopaedics \& Traumatology: Surgery \& Research. 2013 Feb 1;99(1):S1-1.

64. Clement ND, Duckworth AD, McQueen MM, Court-Brown CM. The outcome of proximal humeral fractures in the elderly: predictors of mortality and function. The bone \& joint journal. 2014 Jul;96(7):970-77.

65. Van Eck CF, Klein CM, Rahmi Hea. Morbidity, mortality and cost of osteoporotic fractures-should proximal humerus fractures be taken as seriously as hip fractures? Ann Joint. 2019;4(3):1-7.

66. Torchia MT, Austin DC, Cozzolino N, Jacobowitz L, Bell JE. Acute versus delayed reverse total shoulder arthroplasty for the treatment of proximal humeral fractures in the elderly population: a systematic review and meta-analysis. Journal of Shoulder and Elbow Surgery. 2019. April (28)4:765-73.

67. Seidl A, Sholder D, Warrender W, Livesey M, Williams G, Abboud J, Namdari S. Early versus late reverse shoulder arthroplasty for proximal humerus fractures: does it matter? Archives of Bone and Joint Surgery. 2017 Jul;5(4):213-19. 